\title{
A Model for Predicting Dissolved Organic Carbon Distribution in a Reservoir Water using Fluorescence Spectroscopy
}

Emma H. Goslan, School of Water Sciences, Cranfield University, Cranfield, Bedfordshire MK43 0AL, UK.

Sandrine Voros,

Jenny Banks, Water Quality Technology Development Department, Yorkshire Water, Western Way, Halifax Road, Bradford, BD6 2LZ, UK.

Derek Wilson, Water Quality Technology Development Department, Yorkshire Water, Western Way, Halifax Road, Bradford, BD6 2LZ, UK.

Peter Hillis, United Utilities Service Delivery, Asset Creation - Task Team, Thirlmere House, Lingley Mere, Lingley Green Avenue, Warrington, WA5 3LP, UK.

Andrew T. Campbell, United Utilities Service Delivery, Asset Creation - Task Team, Thirlmere House, Lingley Mere, Lingley Green Avenue, Warrington, WA5 3LP, UK. Simon A. Parsons (corresponding author) School of Water Sciences, Cranfield University, Cranfield, Bedfordshire MK43 0AL, UK. Telephone: +44 (0) 1234 754963, Fax: + 44 (0) 1234 751671. E-mail: s.a.parsons@cranfield.ac.uk 


\begin{abstract}
A number of water treatment works (WTW) in the north of England (UK) have experienced problems in reducing the dissolved organic carbon (DOC) present in the water to a sufficiently low level. The problems are experienced in autumn/winter when the colour increases and the WTW becomes overloaded. However the DOC content of the water varies little throughout the year. To investigate this further, the water was fractionated using resin adsorption techniques into its hydrophobic (fulvic and humic acid fractions) and hydrophilic (acid and non-acid fractions) components. The fractionation process yields useful information on the changing concentration of each fraction but is time consuming and labour intensive. Here, a method of rapidly determining fraction concentration was developed using fluorescence spectroscopy. The model created used synchronous spectra of fractionated material compared against bulk water spectra and predicted the fraction concentrations to within $10 \%$ for a specific water. The model was unable to predict fraction concentrations for waters from a different watershed.
\end{abstract}




\section{Introduction}

The fractionation of dissolved natural organic matter (NOM) from raw waters is typically undertaken using macroporous non-ionic resins (Goslan, E. H. et al., 2002) where it is separated into its hydrophobic acid (humic and fulvic acid) fraction as well as hydrophilic acid and non-acid fractions. The fractionation provides useful information compared to bulk water parameters but is time consuming and labour intensive.

A number of water treatment works (WTW) in the North of England (UK) have recently been experiencing problems reducing the level of disinfection by-product (DBP) precursors, such as dissolved organic carbon (DOC), to a suitably low level at certain times of the year. This occurs when there is an increase in the hydrophobic acid fraction, specifically the fulvic acid fraction (FAF). It would therefore be useful if the DOC distribution could be determined rapidly, without the use of resin fractionation, in order to determine an increase in the FAF. Fluorescence spectroscopy is proposed as such a method.

Fluorescence spectra are usually obtained either by analysing the intensity of emitted light as a function of its excitation wavelength (emission spectra) or by analysing the intensity of light emitted at a fixed wavelength whilst scanning the wavelength of excitation (excitation spectra). When both the excitation and emission wavelengths are scanned simultaneously but the difference between them is kept constant, the resulting spectrum is a synchronous spectrum (Croué, J.-P. et al., 2000). The data from the synchronous scan can be represented as an excitation-emission matrix (EEM) which provides highly detailed information that can be used to identify fluorescent compounds present in complex mixtures. Synchronous spectroscopy provides new information compared to a single scan. The wavelength independent 
fluorescence maximum $\left(\mathrm{Ex}_{\max } / \mathrm{Em}_{\max }\right)$ is not dependent on the wavelength at which fluorescence was stimulated or at which emission was observed because it represents the one combination which results in maximum fluorescence (Coble, P., 1996). Previous work, in the field of fluorescence spectroscopy for characterisation of organic matter, (Coble, P., 1996, Smith, D. S. and Kramer, J. R., 1999) has established that humic substances typically fluoresce in the excitation range of $\sim 300-$ $400 \mathrm{~nm}$ and the emission range of $\sim 400-500 \mathrm{~nm}$.

Due to the relative ease and high sensitivity of optical techniques, numerous studies have examined their potential for determining the DOC content of natural waters (Senesi, N., 1990, Ferrari, G. M. et al., 1996, Mittenzwey, K. H. et al,, 1996, Skoog, A. and Wedborg, M., 1996, Hautaula, K. et al., 2000). With higher resolution spectrometers, and the ability to acquire complete absorption and emission spectra, advances have been made in characterising the source dependent spectral variations of dissolved organic matter (Green, S. A. and Blough, N. V., 1994). Synchronous fluorescence spectroscopy has also been successfully used to distinguish between humic substances isolated from soil and water (Senesi, N. et al., 1989, Patterson H. H. et al., 1992, Pullin, M. J. and Cabaniss, S. E., 1995, Mobed, J. J. et al., 1996, Da Silva, J. C. G. E. and Machado, A. A. S. C., 1997). More recently a method has been proposed by Marhaba, T. F. et al. (2000) that can rapidly identify organic matter fraction concentrations in a water using Spectral Fluorescent Signatures. In this paper, we have carried out a study to investigate the use of fluorescence spectroscopy as a technique for rapidly determining the concentration of fractions in raw water as an alternative to the traditional resin separation technique. The Spectral Fluorescent Signatures (SFS) technique (Marhaba, T. F. et al., 2000) was investigated before developing the method described here. 


\section{Materials and Methods}

Water samples (raw water) were collected from the reservoir inlet at Albert WTW in the Yorkshire Water region in the UK in November 2000, November 2001 and April 2002. Water samples were collected from the reservoir inlet at Rivington WTW in the United Utilities Water region in the UK in April 2001. The parameters of each raw water are reported (Table 1).

The raw water was fractionated by XAD resin adsorption techniques into its hydrophobic acid (HPOA) and hydrophilic acid (HPIA) fractions using an adapted method (Malcolm, R. L. and MacCarthy, P., 1992) that has been described previously (Goslan, E. H. et al., 2002). The HPOA fraction was further separated into its humic acid fraction (HAF) and fulvic acid fraction (FAF) by precipitation of the $\mathrm{HAF}$ at $\mathrm{pH}$ 1. Non-adsorbed material was designated the name hydrophilic non-acid fraction (HPINA). The denaturing of the DOC in the water samples, due to the acid and alkaline conditions used in the fractionation, has been previously discussed (Goslan, E. H. et al., 2002).

Dissolved organic carbon (DOC) measurements were used to determine fraction concentrations. Here, the DOC is defined as the organic carbon that passes through a $0.45 \mu \mathrm{m}$ filter. DOC was measured using a Shimadzu TOC-5000A analyser (Milton Keynes, UK).

Fluorescence measurements were carried out using a Varian Cary Eclipse Spectrophotometer (Middelburg, The Netherlands). The raw water fractions were diluted to concentrations of $0.1,0.2,0.4,0.6,0.8$ and $1.0 \mathrm{mg} \mathrm{L}^{-1}$ (as well as 0.5 and $0.7 \mathrm{mg} \mathrm{L}^{-1}$ for the FAF) using deionised water. The $\mathrm{pH}$ of each sample was adjusted to 7. A synchronous scan was carried out on each sample at each dilution. As with the Spectral Fluorescent Signatures technique (Marhaba, T. F. et al., 2000), this 
involved exciting each sample from 225 to $525 \mathrm{~nm}$. At each excitation level, emission was recorded from excitation $+24 \mathrm{~nm}$ to $633 \mathrm{~nm}$. An optimal stepwise increment of $12 \mathrm{~nm}$ was used for both excitation and emission measurements. For each sample an excitation-emission matrix (EEM) was produced. Good spectroscopic practice was exercised throughout the study. 


\section{Results and Discussion}

\section{Fluorescence of DOC fractions}

The total luminescence spectra for each of the four DOC fractions at $1 \mathrm{mg} \mathrm{L}^{-1} \mathrm{DOC}$ was studied in the form of excitation-emission matrices (EEMs) (Figures 2 to 5). The FAF and HPIA EEMs showed a bimodal peak distribution indicating the presence of two main fluorophores in the macromolecular structure of the dissolved NOM. The HAF EEM had four distinct peaks. The HPINA EEM showed a trimodal distribution with much lower intensity of fluorescence being exhibited when compared with the other fractions. Wavelength pair values for the two major peaks exhibited by each fraction are reported in Table 2 alongside literature values.

Previous analysis of the fractions by High Pressure Size Exclusion Chromatography has shown that the FAF contains smaller molecules than the HAF (Parsons, S. A. et al., 2002). The stronger intensity of fluorescence exhibited by the FAF (Figure 2), when compared to the HAF (Figure 3) (in the excitation area $300-350 \mathrm{~nm}$ ), indicated that smaller sized molecules fluoresce more strongly per mass of carbon. This could be as a result of more efficient energy transfer through internal conversions in the larger molecules (Alberts, J. J. et al., 2000). The presence of a variety of fluorescent structures has been reported as being indigenous in the fulvic macromolecule. These include condensed aromatic moieties bearing various functional groups and unsaturated aliphatic chains (Senesi, N., 1990).

In the literature, wavelength pairs at 278/353 (excitation/emission (nm)) have been reported for protein-like substances and at 337/423 (ex/em (nm)) for fulvic-like substances (Her, N. et al., 2001). A faint peak is observed in the protein-like region in the HAF EEM at 280/325 (ex/em (nm)) (Figure 3). Fulvic acid has also been 
reported to fluoresce in the range 290-340/380-430 (ex/em (nm) (Baker, A. and Genty, D., 2001). Wavelength pairs have been reported for humic-like substances at 310/423 (ex/em (nm)) (Coble, P., 1996). These reported values agree with those observed for the Albert Reservoir fractions (Table 2).

It has been reported by Baker, A. and Lamont-Black, J. (2001) that after the first flush of the hydrological year in the UK (in autumn), fluorescent dissolved organic matter (DOM) had a lower emission wavelength than the annual mean. Furthermore, a second (late winter) organic matter flush comprised fluorescent DOM that had a lower excitation wavelength than the annual mean. The fact that the samples investigated here were taken in November (autumn/winter) could explain the blue shift (shorter wavelengths) in the excitation wavelengths observed for the fulvic- and humic-like fluorescence when compared with other values found in the literature (Alberts, J. J. et al., 2000, Miano, T. M. and Alberts, J. J., 1999).

Marhaba, T. F. et al. (2000) have reported wavelength pairs for hydrophilic acids in the literature. The first wavelength pair in the HPIA EEM at 318/424 (ex/em (nm)) (Figure 4) is in the region of fulvic-like fluorescence but the intensity of fluorescence is much lower than the FAF perhaps indicating less aromaticity and less saturation in the HPIA.

The wavelengths in the first pair shift towards shorter wavelengths for the HPINA fraction signifying a smaller nominal molecular size when compared with the other fractions. The lower intensity of fluorescence indicates a lower degree of aromaticity for the HPINA fraction when compared to the other fractions. A peak for carboxylic acids at 310/400 (ex/em (nm)) was identified in the literature (Alberts, J. J. et al., 2000). A peak is observed in this region in the HPINA fraction EEM (Figure 5). This 
peak at $310 / 400(\mathrm{ex} / \mathrm{em}(\mathrm{nm})$ is also said to be representative of small nitrogen containing compounds (Alberts, J. J. et al., 2000).

\section{Model Development}

When analysing fluorescence spectra, the position of peaks on the EEM that exhibit maximum intensity values are investigated. Typically, an EEM for a sample containing NOM will exhibit two main peaks. The position of these peaks gives information on the types of molecules present. Marhaba. T. F. et al. (2000) found that the areas of maximum intensity of fluorescence were shown to be representative of the concentration of each fraction. The region of the EEMs investigated in the SFS technique was maximum intensity values in the $225-249 \mathrm{~nm}$ excitation region

(Figure 1). Figure 1 is a collation of maximum intensity values reported in the literature, as well as maximum intensity values found in this study, in the form of an EEM.

Another study has reported two intensity maxima observed in each EEM (Coble, P., 1996). One from excitation at the shortest wavelength used (in this case $\sim 260 \mathrm{~nm}$ ) and another from excitation in the region $300-370 \mathrm{~nm}$. The author found it difficult to determine the actual position and shape of the first maxima as the observations only extended to $260 \mathrm{~nm}$. This peak on the edge of the EEM has been previously disregarded (Coble, P., 1996). It is this peak at the limit of observation that Marhaba, T. F. et al. (2000) proposed as being representative of the organic matter in the sample. In a different study the two peaks observed were referred to as fluorescent pairs that were shown on the EEM as a bimodal peak distribution (Alberts, J. J. et al., 2000). In that study the second of the pairs was again at the edge of the observed excitation range. Here, the authors 
simplified the spectra by taking the second derivative of the entire spectra to create four peaks. The chemical identity of this peak has been reported as unknown but typical for aquatic NOM (Blaser, P. et al., 1999). Another study attributes the region of fluorescence at 230-280/310-420 (excitation/emission (nm)) to a single fluorophore such as a protein although it is acknowledged that fluorescence at this excitation wavelength is poorly understood (Baker, A. and Lamont-Black, J., 2001). In the literature, the peaks observed at the limit of observation have been either disregarded or derived to create new data. Only Marhaba, T. F. et al. (2000) have used the data as it stands.

Excitation-emission matrices (EEMs) were produced for all the fractions at varying concentrations. The data from each synchronous scan was saved in a database. Each EEM exhibited at least two major areas of fluorescence. As with the SFS technique (Marhaba, T. F. et al., 2000), we took the region of highest intensity of fluorescence as being representative of each fraction. However, it was found that the information contained in this area could not help to determine fraction concentration, as the peak was too close to the edge of the observations made.

We then looked at the region of organic matter fluorescence (excitation 300-350 $\mathrm{nm} / \mathrm{emission} 300-500 \mathrm{~nm}$ ) as being representative of each fraction. It was found through trial and error that the emission spectrum of raw water at the excitation wavelength of $311 \mathrm{~nm}$ was approximately equal to the sum of the emission spectra of each of the fractions at $311 \mathrm{~nm}$ given that one fraction had a predominant concentration. $311 \mathrm{~nm}$ was the average excitation wavelength for the second maxima of all the fractions measured. The predominant fraction was determined by resin fractionation. 
A Microsoft Excel macro was created to process the data. The steps followed by the macro are illustrated in Figure 6.

Step 1: Once a synchronous scan of the raw water was carried out, the emission spectra at ex $=311 \mathrm{~nm}$ was extracted.

Step 2: The predominant fraction spectra (FAF) at different concentrations was compared against Figure 6 (a) until the concentration that matched the raw water spectra most closely was found (Figure $6(\mathrm{~b})$ ). The closest spectra will be where the squared difference between the spectra is closest to zero.

Step 3: Now the concentration of the predominant fraction was established. To determine the concentration of the remaining three fractions, the spectra for the remaining fraction at each concentration were added to it in all possible combinations until a combination was found that was closest to the raw water spectra (Figure 6 (c)). As there are three remaining fractions at six different concentrations, there are $6^{3}$ combinations.

\section{Initial Testing of Model on Synthetic Waters}

The model was tested on Albert raw water sampled in November 2000. The results are shown in a table that compares the real values as determined from the resin fractionation with the values predicted using the model (Table 3). A close match was expected as the fractions from this water were used to produce the fraction data for the database.

The model was tested on samples A to $\mathrm{C}$ that were artificially created from solutions of the isolated fractions. Theses synthetic waters were made to test the model on HAF and FAF rich waters. Table 4 shows the real proportion of each fraction in the 
samples for analysis compared to the fraction concentrations predicted using the model.

With sample A, the predicted results are within $\pm 3 \%$ of the 'real values' for all fractions. The predicted results are expected to be very close to the real results as sample A was made with the same proportions as the November raw water (2000) that was used to create the database. With sample $B$, the predicted results are within \pm 4 $\%$ of the real values. With sample B, the principal fraction is the HAF. This shows that even when the principal fraction is changed, the method gives an accurate result. Sample $\mathrm{C}$ is accurate to $\pm 9 \%$. With sample $\mathrm{C}$, the FAF concentration was underestimated by the model thus leading to an overestimation of the other fraction concentrations.

Synthetic waters with a hydrophilic fraction as the principal fraction were not made as the water from Albert Reservoir has been shown to be mainly hydrophobic throughout the year (Goslan, E. H. et al., 2002). It is also thought that the prediction of hydrophilic fraction (HPIA and HPINA) concentrations may be less accurate due to their lower intensity of fluorescence when compared with the more hydrophobic fractions (FAF and HAF).

\section{Testing of Model on Natural Waters}

The model was tested on Albert raw water taken in November 2001. The results are shown in a table (Table 3 ) that compares the real values as determined from the resin fractionation with the values predicted using the model.

The results from the model are very close to the results determined by resin fractionation for the FAF and HAF $( \pm 2 \%)$ but are less accurate for the more 
hydrophilic fractions $( \pm 6 \%)$. This could be attributed to the lower intensity of fluorescence exhibited by the more hydrophilic fractions. The method was tested further on Albert raw water, this time taken in April 2002. The results are shown (Table 3$)$. The results here are less accurate $( \pm 8 \%)$ than observed with the water sampled in November. It has been reported that the position of the excitation and emission maxima will change seasonally (Baker, A. and Lamont-Black, J., 2001). This could account for the less accurate results found when analysing water from April with a database set up using November water.

\section{Use of the Model on Other Watersheds}

The model was tested on raw water from Rivington WTW in the North West of England. The results are shown (Table 3). With an error of $>25 \%$ for the HAF, the results show that the model is unable to predict the concentration of fractions for a water that has not been used to create the fraction database. Therefore, for the model to work on a different water, a fraction database for that water would need to be set up. This would involve resin fractionation followed by a synchronous scan of each fraction at varying concentrations to produce the fraction database.

\section{Practical use of the model}

The objective of this study was to determine if the seasonal change in DOC concentration and character could be determined rapidly and accurately using fluorescence spectroscopy in order that treatment can be adapted accordingly. Seasonal changes in the nature of DOC can have significant impact on water treatment processes. There is therefore a need to characterise the nature of the organic matter entering a treatment works. Whilst methods such as HPSEC can fingerprint 
organic material it does not provide the same level of information on treatability as knowing the fraction distribution. Traditional resin fractionation methods are time consuming and labour intensive. Even if clean resin is available it will take many days to determine the fraction distribution. By using the model it is possible to predict sudden changes in DOC distribution within an hour which means that treatment at the WTW can be adapted to cope. The information gleaned through fractionation confirms the need to consider DOC as a complex mixture of organics rather than a bulk parameter (Goslan, E. H. et al., 2002).

\section{Conclusions}

- The model described here can be used for a specific site to rapidly determine changes in the DOC distribution in a raw water.

- The model contains a database of fractions at different concentrations for comparison with a raw water sample.

- Compared with resin fractionation which can take many days to determine fraction distribution, this model can determine fraction distribution within an hour (once the model has been set up for a particular water).

- Although the model reported here has shown potential for predicting the concentrations of these fractions, it needs to be validated further with more fractionation data.

\section{Acknowledgements}

The authors would like to express gratitude to Yorkshire Water and United Utilities for sponsoring this work. The opinions expressed are those of the authors and do not necessarily reflect the views of Yorkshire Water or United Utilities. The authors would also like to thank the Engineering and Physical Science Research Council for funding this project. 


\section{References}

Alberts, J. J., Takàcs, M. and Pattanayek, M. (2000) Natural Organic Matter from a Norwegian Lake: Possible Structural Changes Resulting from Lake Acidification. In: Humic Substances: Versatile Components of Plants, Soil and Water, eds Ghabbour E. A. and Davies G. The Royal Society of Chemistry, Cambridge, UK.

Baker, A. and Genty, D. (1999) Fluorescence Wavelength and Intensity Variations of Cavewaters. Journal of Hydrology 217, 19-34

Baker, A. and Lamont-Black, J. (2001) Fluorescence of Dissolved Organic Matter as a Natural Tracer of Groundwater. Groundwater 39 (5), 745-750

Blaser, P., Heim, A. and Luster, J. (1999) Total Luminescence Spectroscopy of NOM-Typing Samples and Their Aluminium Complexes. Environment International $252 / 3,285-293$

Coble, P. (1996) Characterization of Marine and Terrestrial DOM in Seawater using Excitation-Emission Matrix Spectroscopy. Marine Chemistry 51, 325-346

Croué, J.-P., Korshin, G. V. and Benjamin, M. (2000) Characterization of Natural Organic Matter in Drinking Water. American Water Works Association Research Foundation, Denver, CO. No. 90780

Da Silva, J. C. G. E. and Machado, A. A. S. C. (1997) Procedure for the Classification of Fulvic Acids and Similar Substances based on the Variation of $\mathrm{pH}$ of their Synchronous Fluorescence Spectra. Analyst 122, 1299-1305

Ferrari, G. M., Dowell, M. D., Grossi, S. and Targa, C. C. (1996) Relationship between the Optical Properties of Chromophoric Dissolved Organic Matter and Total Concentration of Dissolved Organic Carbon in the Southern Baltic Sea Region. Marine Chemistry 55, 299-316

Goslan, E. H., Fearing, D. A., Banks, J., Wilson, D., Hillis, P., Campbell, A. T. and Parsons, S. A. (2002) Seasonal variations in the disinfection by-product precursor profile of a reservoir water. Journal of Water Supply: Research and Technology AQUA 51, 475 - 482

Green, S. A. and Blough, N. V. (1994) Optical Absorbance and Fluorescence Properties of Chromophoric Dissolved Organic Matter in Natural Waters. Limnology and Oceanography 38, 1903-1916

Hautaula, K., Peuravuori, J. and Pihlaja, K. (2000) Measurement of Aquatic Humus Content by Spectroscopic Analysis. Water Research 34(1), 246-258

Her, N., Amy, G., Sohn, J. and Yoon, Y. (2001) Charaterization of DOM as a Function of MW by HPLC-SEC using UVA, DOC and Fluorescence Detection. In: Proceedings of the Water Quality Technology Conference of the American Water Works Association Nashville, November 11-15 
Malcolm, R. L., \& MacCarthy, P. (1992) Quantitative Evaluation of XAD-8 and XAD-4 Resins used in Tandem for Removing Organic Solutes from Water. Environmental International 18, 597-607.

Marhaba, T. F., Van, D. and Lippincott, R. L. (2000) Rapid Identification of Dissolved Organic Matter Fractions in Water by Spectral Fluorescent Signatures. Water Research 34 (14), 3543-3550

McKnight, D.M., Boyer, E., Westerhoff, P., Doran, P., Kulbe, T. and Anderson, D. (2001) Spectrofluorometric characterization of dissolved organic matter for indication of precursor organic material and aromaticity. Limnology and Oceanography 46(1), $38-48$

Miano, T. M. and Alberts, J. J. (1999) Fluorescence Behaviour of Molecular Size Fractions of Suwannee River Water. The Effect of Photo-Oxidation. In Understanding Humic Substances: Advanced Methods, Properties and Applications, eds Ghabbour E. A. and Davies G. The Royal Society of Chemistry, Cambridge, UK.

Mittenzwey, K. H., Reuter, R. and Gitelson, A. (1996) Analysis of Dissolved Humic Substances in Eutrophic Waters using the Fluorescence of Natural Samples. Internationale Revue der gesamten Hydrobiologie 81(1), 1-12

Mobed, J. J., Hemmingsen, S. L. Autry, J. L. and McGown, L. B. (1996) Fluorescence Characterization of IHSS Humic Substances: Total Luminescence Spectra with Absorbance Correction. Environmental Science and Technology 30, 3061-3065

Parsons, S. A., Goslan, E. H., Jarvis, P. R., Hurst, A. M. and Fearing, D. A. (2002) NOM - The relationship between character and treatability. In: Proceedings of Natural Organic Matter Characterisation and Treatment, Cranfield University, 15 May, UK.

Patterson, H. H., Cronan, C. S., Lakshman, S., Plankey, B. J. and Taylor, T. A. (1992) Comparison of Soil Fulvic Acids using Synchronous Scan Fluorescence Spectroscopy, FTIR, Titration and Metal Complexation Kinetics. The Science of the Total Environment 113, 179-196

Pullin, M. J. and Cabaniss, S. E (1995) Rank Analysis of the pH-Dependent Synchronous Fluorescence Spectra of Six Standard Humic Substances. Environmental Science and Technology 29, 1460-1467

Senesi, N., Miano, T. M., Provenzano, M. R. and Brunetti, G. (1989) Spectroscopic and Compositional Comparative Characterization of IHSS Reference and Standard Fulvic and Humic Acids of Various Origins. The Science of the Total Environment 81/82, 143-156 
Senesi, N. (1990) Molecular and Quantitative Aspects of the Chemistry of Fulvic Acid and its Interactions with Metal-Ions and Organic Chemicals. 2. The Fluorescence Spectroscopy Approach. Analytica Chimica Acta 232(1), 77-106

Skoog, A., Wedborg, M. and Fogelqvist, E. (1996) Photobleaching of Fluoresence and the Organic Carbon Concentration in a Coastal Environment. Marine Chemistry 55, 333-345

Smith, D. S. and Kramer, J. R. (1999) Fluorescence Analysis for Multi-site Aluminium Binding to Natural Organic Matter. Environment International, 25 (2/3), 295-306 
Table 1 Raw Water Parameters

\begin{tabular}{|l|c|c|c|c|c|}
\hline Sample & $\mathrm{pH}$ & $\begin{array}{c}\text { DOC } \\
\left(\mathrm{mg} \mathrm{L}^{-1}\right)\end{array}$ & $\begin{array}{c}\text { UV absorbance at } \\
254 \mathrm{~nm}\left(\mathrm{~m}^{-1}\right)\end{array}$ & $\begin{array}{c}\text { SUVA } \\
\left(\mathrm{m}^{-1} . \mathrm{L} \mathrm{mg}^{-1} \mathrm{C}\right)\end{array}$ & $\begin{array}{c}\text { THM } \\
\left(\mu \mathrm{g} \mathrm{L}^{-1}\right)\end{array}$ \\
\hline Albert (Nov 2000) & 5.0 & 10.2 & 60.2 & 5.9 & 907.5 \\
\hline Albert (Nov 2001) & 5.2 & 9.9 & 48.0 & 4.9 & 563.8 \\
\hline Albert (Apr 2002) & 5.9 & 7.5 & 38.1 & 5.1 & 126.8 \\
\hline Rivington (Feb 2001) & 7.1 & 6.1 & 24.6 & 3.7 & 143.5 \\
\hline
\end{tabular}


Table 2 Comparison of luminescence data of Albert November Raw Water (2000) fractions with literature values

\begin{tabular}{|c|c|c|c|}
\hline \multirow[t]{2}{*}{ Reference } & \multirow{2}{*}{$\begin{array}{c}\text { Sample } \\
\text { identification } \\
\end{array}$} & \multicolumn{2}{|c|}{ Excitation-Emission wavelength pairs (nm) } \\
\hline & & $1^{\text {st }}$ pair & $2^{\text {nd }}$ pair \\
\hline Coble, P. (1996) & Freshwater HA & 310,428 & Disregarded \\
\hline Coble, P. (1996) & Freshwater HA & 310,423 & Disregarded \\
\hline Coble, P. (1996) & FA & 310,419 & Disregarded \\
\hline $\begin{array}{l}\text { Miano, T. M. and } \\
\text { Alberts, J. J. (1999) }\end{array}$ & $\begin{array}{c}\text { Suwannee River } \\
\text { Water }\end{array}$ & 352,453 & 252,450 \\
\hline $\begin{array}{l}\text { Miano, T. M. and } \\
\text { Alberts, J. J. (1999) }\end{array}$ & $\begin{array}{l}\text { Suwannee River } \\
\text { Water }\end{array}$ & 355,448 & 245,442 \\
\hline $\begin{array}{l}\text { Alberts, J. J. et al. } \\
(2000)\end{array}$ & $\begin{array}{c}\text { Norwegian Lake } \\
\text { Water }\end{array}$ & 330,437 & 225,428 \\
\hline $\begin{array}{l}\text { Alberts, J. J. et al. } \\
(2000)\end{array}$ & $\begin{array}{c}\text { Norwegian Lake } \\
\text { Water } \\
\end{array}$ & 335,438 & 225,426 \\
\hline $\begin{array}{c}\text { Marhaba, T. F. et al. } \\
(2000)\end{array}$ & River Water & & \\
\hline $\begin{array}{c}\text { Marhaba, T. F. et al. } \\
(2000)\end{array}$ & HPO-A & $225-237,345-357$ & Not reported \\
\hline $\begin{array}{c}\text { Marhaba, T. F. et al. } \\
(2000)\end{array}$ & HPO-B & $225-237,357-369$ & Not reported \\
\hline $\begin{array}{c}\text { Marhaba, T. F. et al. } \\
(2000)\end{array}$ & HPO-N & $225,609-621$ & Not reported \\
\hline $\begin{array}{c}\text { Marhaba, T. F. et al. } \\
(2000)\end{array}$ & HPI-A & $237-249,417-429$ & Not reported \\
\hline $\begin{array}{c}\text { Marhaba, T. F. et al. } \\
(2000)\end{array}$ & HPI-B & $225-237,369-381$ & Not reported \\
\hline $\begin{array}{c}\text { Marhaba, T. F. et al. } \\
(2000)\end{array}$ & HPI-N & $225-237,309-321$ & Not reported \\
\hline $\begin{array}{l}\text { Baker, A. and Lamont- } \\
\text { Black, J. (2001) }\end{array}$ & Borehole Water & & \\
\hline $\begin{array}{l}\text { Baker, A. and Lamont- } \\
\text { Black , J. (2001) }\end{array}$ & Fulvic like centre & 320,407 & None reported \\
\hline $\begin{array}{l}\text { Baker, A. and Lamont- } \\
\text { Black , J. (2001) }\end{array}$ & Protein like centre & 278,347 & None reported \\
\hline $\begin{array}{c}\text { McKnight, D. M. et al. } \\
(2001)\end{array}$ & Lake FA & 320,406 & 230,412 \\
\hline Her, N. et al. (2001) & Suwannee River & & \\
\hline Her, N. et al. (2001) & HA & 325,452 & 261,457 \\
\hline Her, N. et al. (2001) & FA & 320,443 & 245,445 \\
\hline This work & FAF & 314,423 & 226,593 \\
\hline This work & HAF & 305,457 & 227,425 \\
\hline This work & HPIA & 318,424 & 226,625 \\
\hline This work & HPINA & 307,390 & 225,351 \\
\hline
\end{tabular}

HPO-A, HPO-B, HPO-N - Hydrophobic acid, base and neutral

HPI-A, HPI-B, HPI-N - Hydrophilic acid, base and neutral

HA - Humic acid, FA - Fulvic acid

FAF - Fulvic acid fraction, HAF - Humic acid fraction

HPIA - Hydrophilic acid fraction, HPINA - Hydrophilic non-acid fraction 
Table 3 Real vs predicted DOC $\left(\mathrm{mg} \mathrm{L}^{-1}\right)$ values of natural samples

\begin{tabular}{|c|c|c|c|c|c|c|c|c|}
\hline & \multicolumn{2}{|c|}{ FAF } & \multicolumn{2}{c|}{ HAF } & \multicolumn{2}{c|}{ HPIA } & \multicolumn{2}{c|}{ HPINA } \\
\hline Sample & Real & Pred. & Real & Pred. & Real & Pred. & Real & Pred. \\
\hline ALB00 & 6.2 & 6.2 & 1.8 & 1.5 & 0.8 & 0.9 & 1.3 & 1.5 \\
ALB01 & 4.2 & 4.4 & 2.4 & 2.4 & 1.7 & 1.1 & 1.7 & 2.1 \\
ALB02 & 3.9 & 3.3 & 1.5 & 1.7 & 0.9 & 0.9 & 1.2 & 1.7 \\
RIV01 & 1.4 & 0.4 & 2.6 & 4.3 & 0.4 & 0.4 & 1.7 & 1.0 \\
\hline
\end{tabular}

Key

ALB00 - Albert Raw Water November 2000

ALB01 - Albert Raw Water November 2001

ALB02 - Albert Raw Water April 2002

ALB03 - Rivington Raw Water February 2001 
Table $4 \quad$ Real vs predicted proportions of synthetic water samples

\begin{tabular}{|c|c|c|c|c|c|c|c|c|}
\hline & \multicolumn{2}{|c|}{ FAF (\%) } & \multicolumn{2}{c|}{ HAF (\%) } & \multicolumn{2}{c|}{ HPIA (\%) } & \multicolumn{2}{c|}{ HPINA (\%) } \\
\hline Sample & Real & Pred. & Real & Pred. & Real & Pred. & Real & Pred. \\
\hline A & 61 & 58 & 18 & 19 & 8 & 8 & 13 & 14 \\
B & 13 & 11 & 65 & 61 & 9 & 10 & 14 & 18 \\
C & 79 & 70 & 4 & 9 & 4 & 7 & 13 & 14 \\
\hline
\end{tabular}




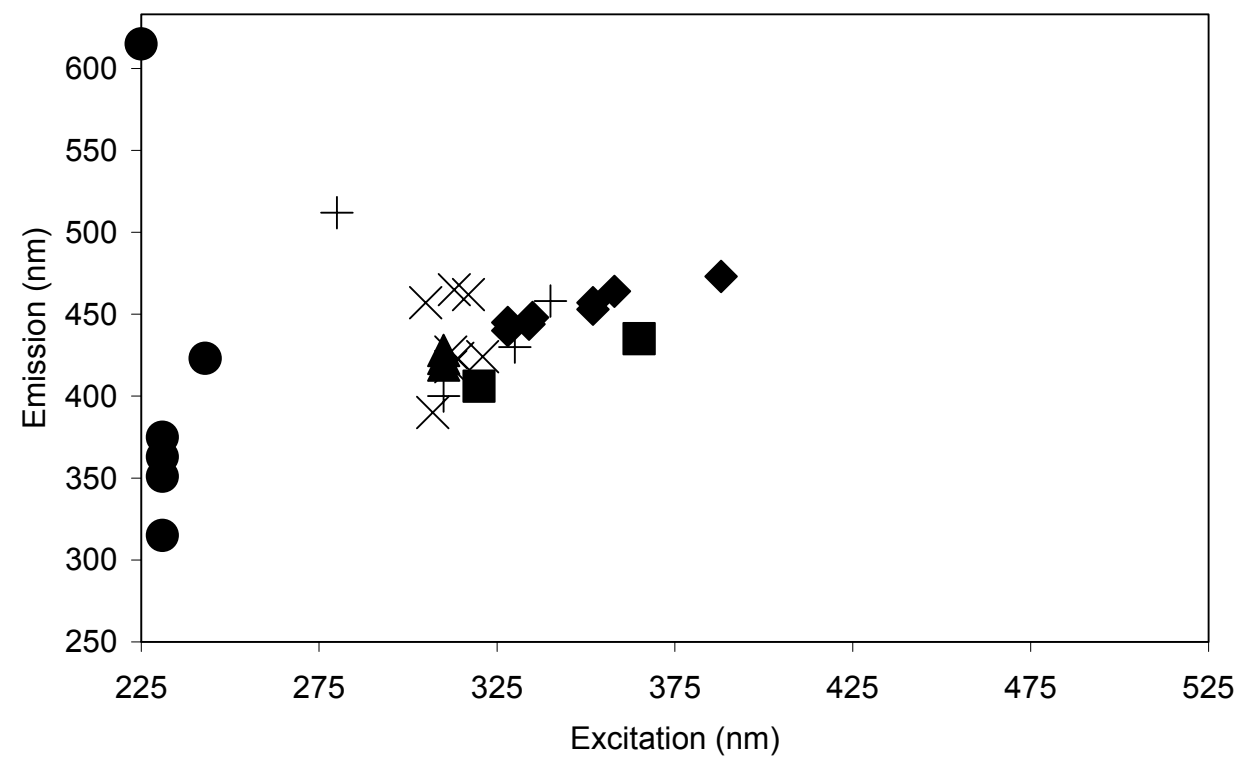

Figure 1 Fraction excitation and emission wavelength maxima

Key

Coble, P. (1996)

Marhaba, T. F. et al. (2000)

Alberts, J. J. et al. (2000) +,

Miano, T. M. and Alberts, J. J. (1999)

McKnight, D. M. et al. (2001) $\square$,

this work $x$ 


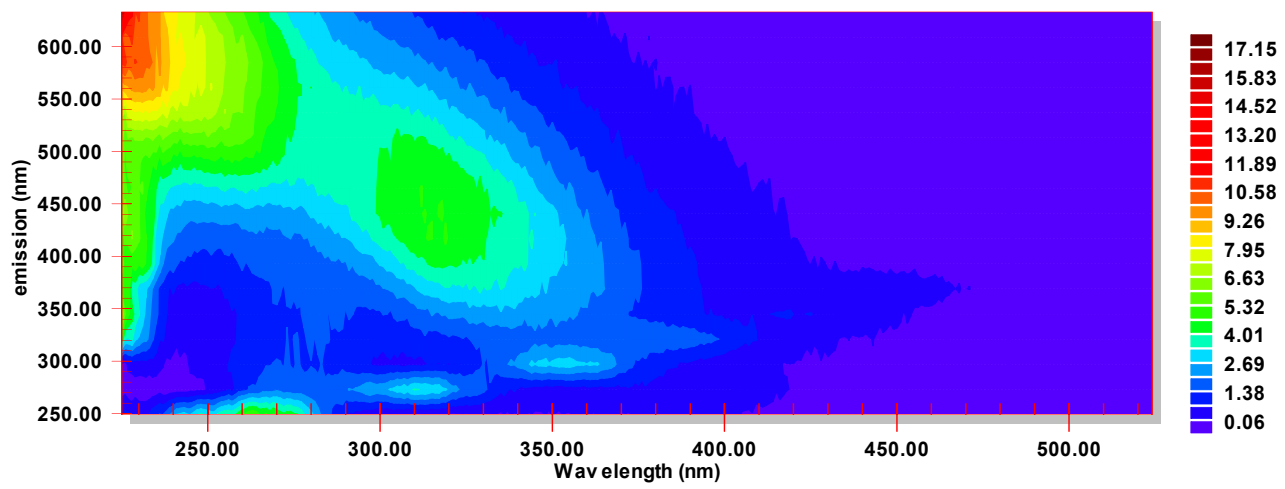

Figure 2 Fulvic Acid Fraction EEM 


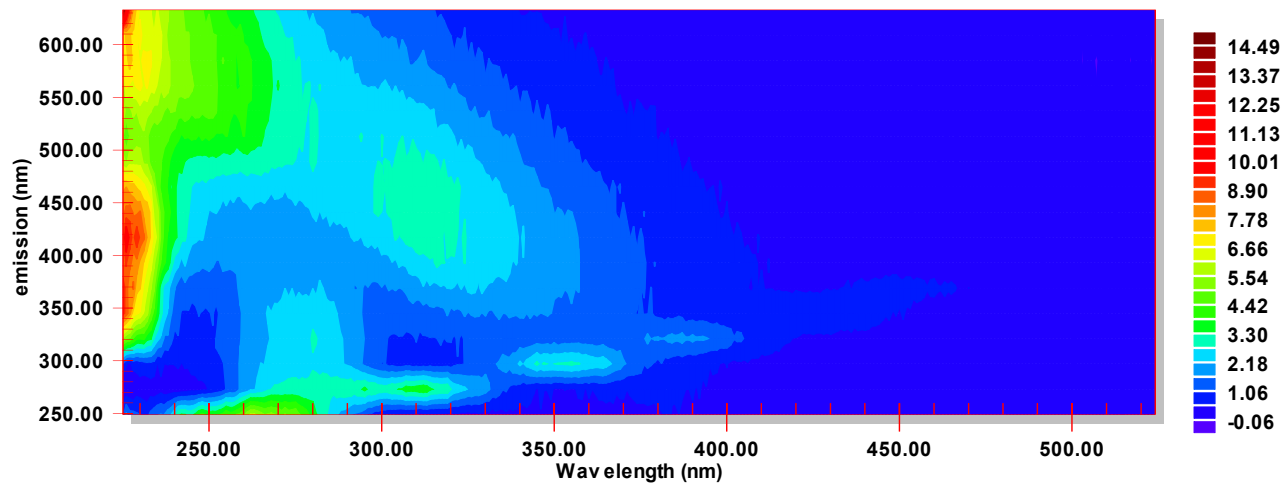

Figure 3 Humic Acid Fraction EEM 


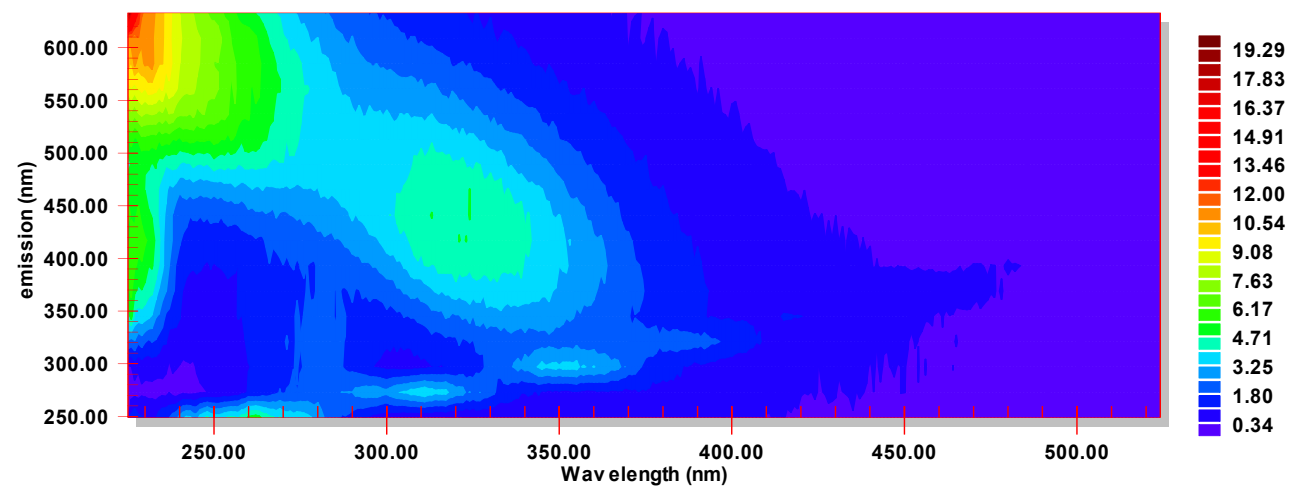

Figure $4 \quad$ Hydrophilic Acid Fraction EEM 


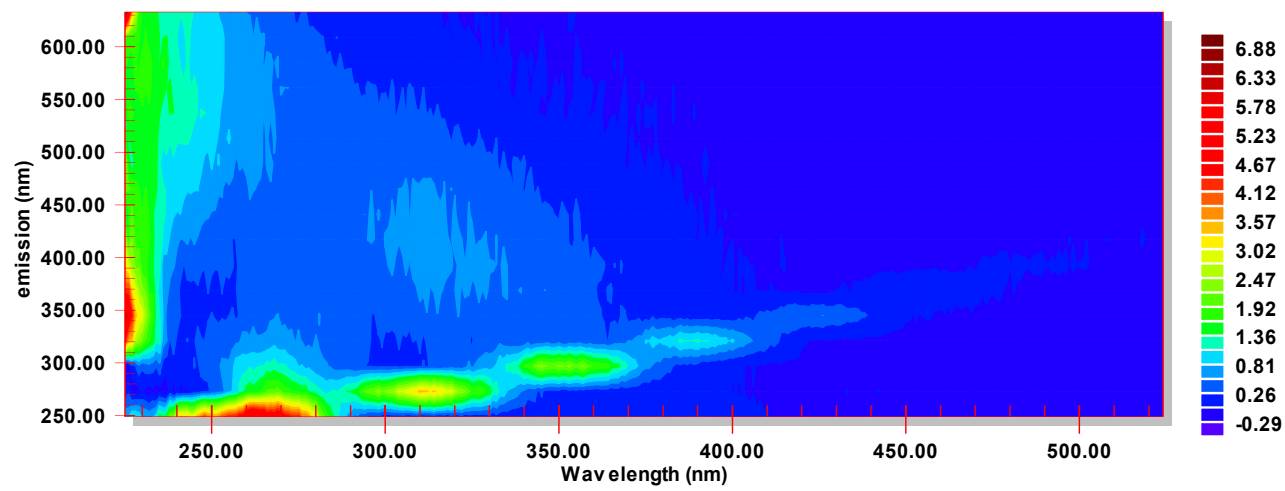

Figure 5 Hydrophilic Non-Acid Fraction EEM 


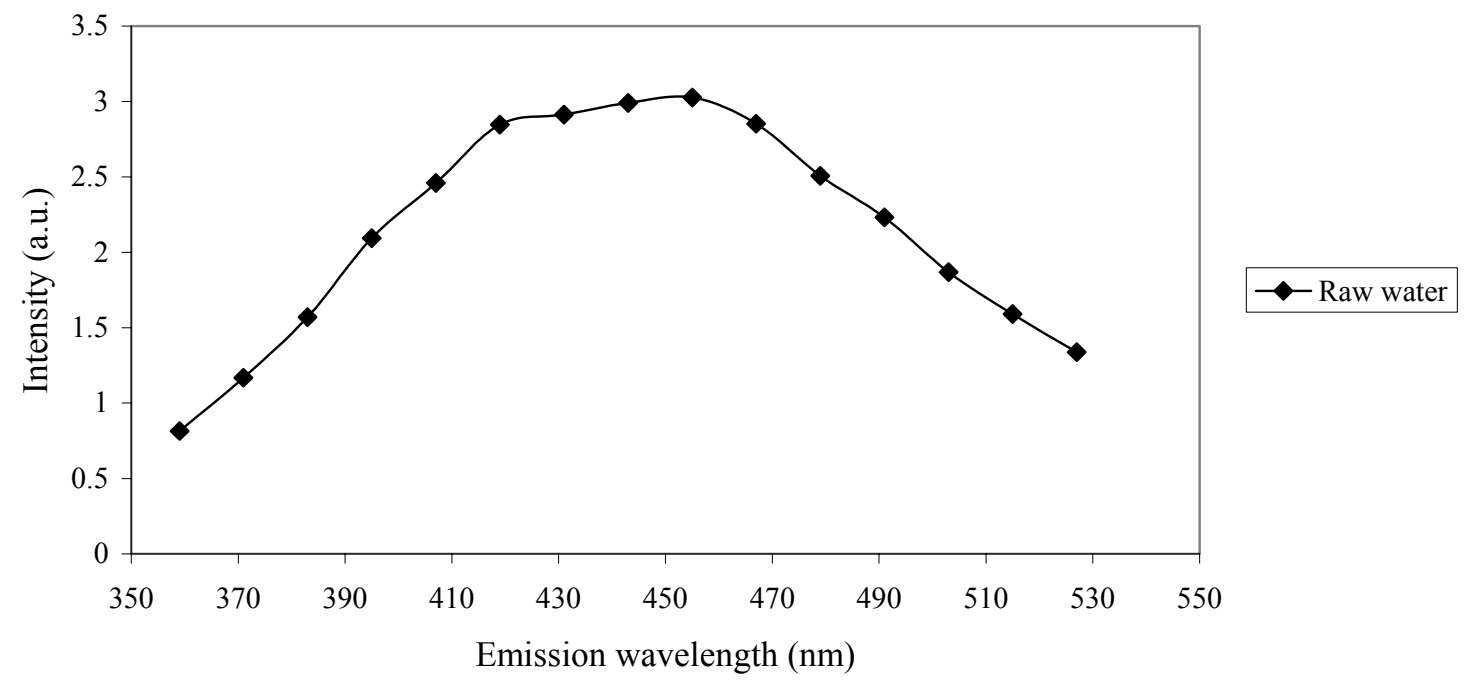

Figure 6 (a) Raw water emission spectra at excitation $=311 \mathrm{~nm}$
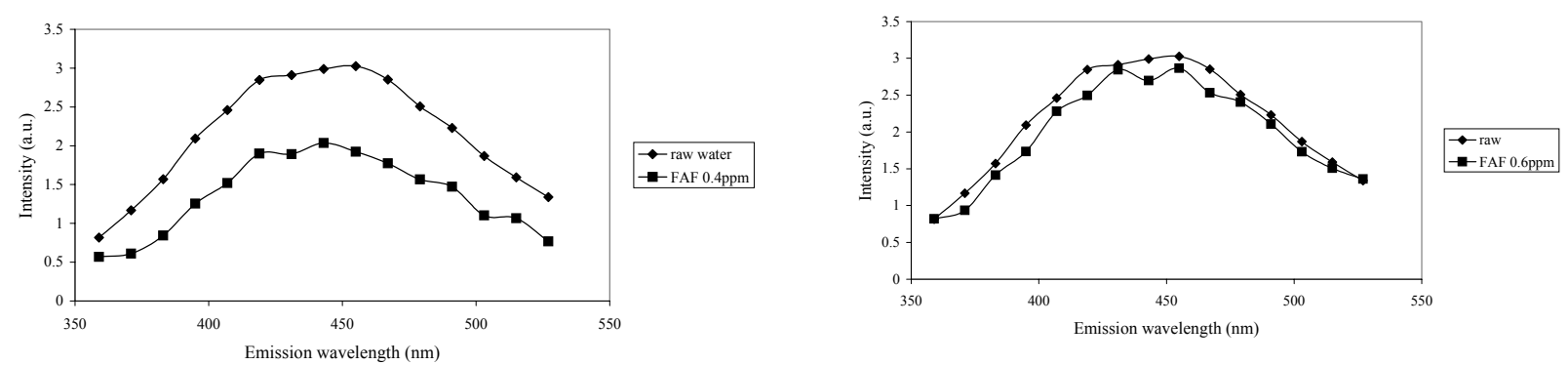

Figure 6 (b) Comparison of raw water emission spectra at excitation $=311 \mathrm{~nm}$ with predominant fraction at different concentrations

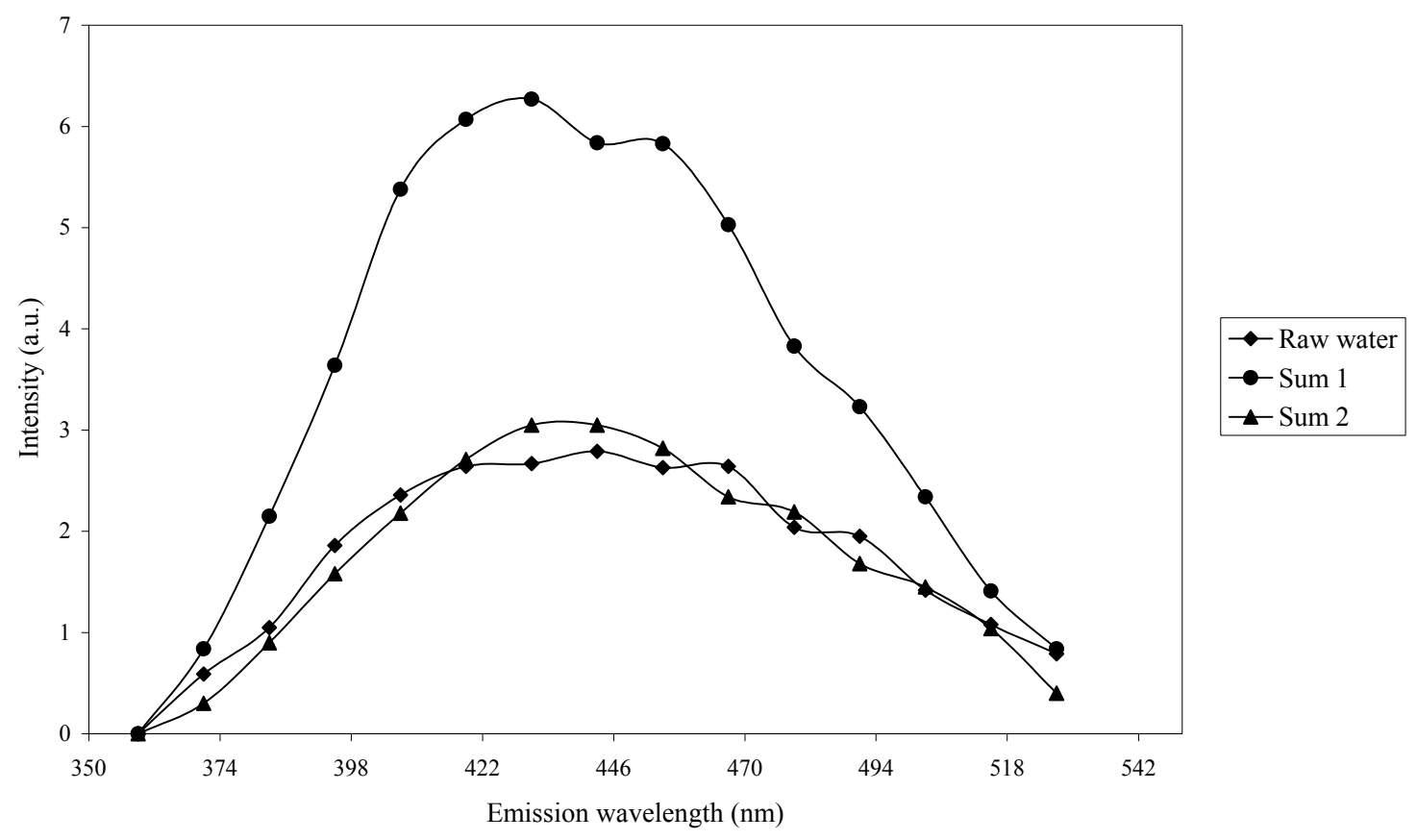

Figure 6 (c) Comparison of summed fractions with raw water emission spectra 